\title{
REFLEXÕES A PROPÓSITO DE ALGUMAS CIDADES DO BRASIL $^{1}$
}

\author{
ORLANDO RIBEIRO*
}

Os geógrafos têm várias maneiras de viajar. Uns fazem uma longa e intensa preparação bibliográfica e cartográfica e, quando abordam uma região desconhecida, formularam já os temas que se propõem aprofundar — não vão ver terras novas, vão observar isto ou aquilo e encontrar in loco a confirmação das idéias que levam antecipadamente no espírito. Para tanto, bastam uns dias, às vezes umas horas e, nesta recolha selectiva de dados, pode, ao fim de pouco tempo, passar-se a outros temas ou outros lugares. É inegável que este processo permite esclarecer rapidamente certos pontos precisos e satisfaz uma das mais obsessivas aspirações dos nossos dias - ganhar tempo. Mas, para quem persiste em ver na Geografia não uma «técnica» de resolver problemas mas uma «arte» de observar e descrever compreensivamente a originalidade dos lugares, é grato poder abordar terras novas com olhos desprevenidos, sem se furtar por isso às aproximações que no seu espírito se vão estabelecendo com os dados das suas anteriores experiências.

Numa terra como o Brasil, e a despeito do caldeamento de raças que aí se operou nos últimos três quartos de século certamente neste género uma das experiências de maior amplitude e maior significado no Globo o geógrafo português dificilmente se furtará referir aos seus esquemas familiares larga parte das suas observações. De facto, muitas coisas lhe recordam a pátria: o ambiente das velhas cidades do litoral, as casasgrandes das lavoura de cana, espécie de «montes» alentejanos com a sua complexa clientela rural (ali fortemente matizada de sangue negro), mesmo

1 Texto de publicação inédita no Brasil, extraído de: Ribeiro, Orlando. Opúsculos Geográficos, Vol.5 - Temas Urbanos. Lisboa: Fundação Calouste Gulbenkian, 1994. Pp. 471-475.

* Orlando Ribeiro (1911-1997), professor da Universidade de Lisboa, foi um dos maiores geógrafos portugueses e considerado o grande renovador da geografia portuguesa no século XX. Informações sobre sua vida e obra na internet: http://www.orlandoribeiro.info/home.htm 
alguns recantos marítimos e comerciais poupados pela renovação de grandes metrópoles, como o Rio e o Recife, onde insensivelmente se evocam os bairros velhos da Ribeira do Porto, povoados de embarcadiços e de mesteirais. Mas, ao contrário do Peru, onde o cunho espanhol se encontra fortemente impresso não só nas cidades, que são uma réplica impressionante das da Extremadura, mas na organização do campo à roda delas, com suas hortas e «tapiales» de culturas mimosas, no meio das vastas extensões de sequeiro ou de aridez, no Brasil andam-se léguas onde em vão se procura qualquer traço português na sua paisagem rural.

Uma lavoura «cabocla» precedida da derrubada e da queimada, instável nos seus processos rudimentares de conquista da terra, os regos correndo pelo mais íngreme da encosta a que nenhum socalco retarda a irremissível degradação, uma organização da terra cultivada, que, para além dos retalhos de policultura estabelecida em torno do milho e da mandioca, base da alimentação rural, ondula ao sabor de todos os ventos da especulação, tanto se orientando para a produção de café como para a cria de zebus, consoante o apelo, não raro ilusório ou hesitante dos grandes mercados: tais são as suas imagens essenciais. Esta terra, que tantas vezes nos mostra as cicatrizes da depredação, na floresta emagrecida e no solo descarnado, raro nos dá aquela impressão de maturidade, de organização aperfeiçoada pelo tempo, que a cada parcela determina uma função e cada grupo de culturas colocou no lugar mais adequado. Pelo seu aspecto instável e incompleto, a paisagem rural da maior extensão do Brasil aparenta-se bem às terras pobres da zona tropical: se nada recorda a Europa, insensivelmente acodem ao espírito símiles africanos. Até a própria palavra «campo», que em Portugal designa tanto o conjunto da terra cultivada, como e seu elemento mais cuidado e importante, destinado a obter cereais de pão, tornou no Brasil sentido oposto, de paisagem aberta e abandonada, por onde podem ter passado os flagelos da queimada e do rebanho, mas sem que o homem nela deixasse outros sinais de presença, além das marcas da sua depredação; terra que se estragou sem a menor preocupação de a conquistar.

Destes «descampados» onde a aglomeração rural, típica de pelo menos metade de Portugal, é completamente desconhecida (no Brasil não há aldeias, mas apenas casas esparsas ou centros de grande lavoura ou criatório) surgem, de longe em longe, cidades a que em vão se buscaria qualquer filiação em paradigmas portugueses. Locais de troca e de atracção, nós distantes duma rede de grandes malhas, estas urbes pioneiras, traçadas à larga em terras vazias, onde se abrem ruas e se demarcam «loteamentos» no mato com uma esperança logo ultrapassada de 
construção, crescem num ritmo acelerado fazendo à sua roda um vazio mais desolador. Impressionam, num estado progressivo como São Paulo, esta vigorosa proliferação urbana, as suas causas variáveis mas sempre em torno duma economia de especulação de ritmo sacudido e o seu destino paradoxal e inquietante: cada vez mais gente integrando-se num estilo de vida urbano mas vivendo, ao fim e ao cabo, da produção duma terra rapidamente exaurida. À roda da urbe, pouco mais do que a desolação e o abandono.

Para um geógrafo mediterrâneo que pela primeira vez se defronta com uma grande metrópole de estilo «americano», como é de facto São Paulo, tanto pela floresta de arranha-céus do centro, como pelos jardins «residenciais» que a rodeiam e a que não falta tranquilidade e encanto, a ausência de uma periferia rural é talvez o seu traço mais impressionante. De facto, esta aglomeração gigantesca não tem «arredores». Que se destruam bairros a que na Europa se chamariam «novos», por uma espécie de mística do reconstruir em altura, choca menos do que ver, envolvendo a cidade, uma cintura de terras estéreis, desertas e abandonadas. Solos mais cedo ocupados, foram os primeiros a esgotar-se; a gente rural foi devorada pela enorme irradiação da grande metrópole e atraída pelo seu formidável apelo de mão-de-obra. Este se estende tão longe, que se vêem, pelas estradas poeirentas do Nordeste, passar dezenas de camiões carregados de «retirantes», famílias promiscuamente apinhadas, fugindo à seca na miragem de encontrar trabalho - não admira que à roda, da grande cidade sugadora nada mais reste do que alguns casebres abandonados e, aqui e ali, por entre um matagal que não recobra a pujança primitiva, o desenho mais apagado dum antigo terreno de cultura! Que enorme diferença em relação a Lima, por exemplo, cidade inteiramente «europeia» e tão espanhola pelo ambiente das suas praças, ruas e pátios interiores das casas, como pela huerta que a envolve, criada à força de regras e de engenho, no sopé desértico da Cordilheira dos Andes! Aqui, como na Espanha árida, especialmente na Andaluzia e no Levante, a urbe é inseparável da sua periferia rural: insensivelmente, passa-se dos casebres que formam, à roda de tantas cidades, a sua cintura de pobreza, às primeiras casas rurais, abrindo-se para a horta mimosa e vendo correr, ao pé da porta, a acéquia que venceu a pobreza da areia e extremada secura do clima. No Brasil, pelo menos nas suas cidades mais novas ou mais progressivas, o amontoado de casas surge muita vez bruscamente, como uma condensação de gente no meio de um deserto humano.

Estas imagens levam-nos a reflectir sobre o verdadeiro carácter da expansão portuguesa. O Brasil é ainda hoje o principal chamariz da 
emigração portuguesa: mas esta, recrutada de preferência no Norte do Pais e entre a gente do campo dirige-se quase exclusivamente para as cidades ou os entrepostos de comércio. Não há no Brasil nenhuma paisagem rural que possa comparar-se às que para aí transpuseram os Alemães criadores de gado no vale do Itajaí, os Italianos vinhateiros no Estado de São Paulo, os Japoneses hortelões aqui e nos arredores de Belo Horizonte; ou até os Negros de origem guineense, camponeses por excelência num «continente de camponeses», que desenvolveram, no Recôncavo da Bahia, uma réplica impressionante da agricultura africana. $\ddot{\mathrm{E}}$ vulgar encontrar Portugueses entre caixeiros de lojas ou retalhistas das cidades, exercendo todos os pequenos mesteres urbanos, e, embora cada vez em menor escala, parte do comércio e da indústria dos grandes centros estão em suas mãos. Nas cidades do Norte do Brasil, eles formam sempre a principal colónia estrangeira, não raro a única que sobressai, pelo número ou pela actividade. Em Belém, por exemplo, desde carregadores, humildes artífices, retalhistas do mercado, até aos principais potentados da finança e do comércio, através duma escala social muito extensa e variada, achamo-los representados em todos os degraus; com maior surpresa ainda os descobrimos perdidos no fundo dum remoto igarapé do Amazonas, vendendo de tudo e comprando borracha, madeira e peles na sua casaentreposto levantada sobre a estacaria; mas Portugueses trabalhando a terra, dirigindo explorações agrícolas ou investindo capital em riqueza fundiária, apontam-se sempre, entre emigrantes de outra origem, como uma excepção.

Há um provérbio que diz: «de tudo se faz negócio, até de cascas de alhos». Se as grandes riquezas que passaram por Lisboa no tempo dos Descobrimentos e foram fazer a fortuna dos banqueiros holandeses e derramar a abundância nas feiras de Flandres, mostram a incapacidade financeira do Português, sempre que ela exija ampla visão, o seu feitio de «traficante» - almocreve, bufarinheiro, tendeiro, lojista ou feirante -, trabalhador, persistente, oscilando tantas vezes entre a honestidade e a astúcia, está amplamente documentado na atracção que estes modos de vida exercem sobre todos os trabalhadores da terra. Fora das suas leiras natais, que não raro abandona para escapar à dupla condenação do trabalho rude e de um passadio que roça pela miséria, o Português é, acima de tudo, homem da cidade ou do entreposto, da loja, da feira, da quitanda, da tendinha, às vezes exercendo com energia mesteres humildes, passando mal para amealhar, mas fugindo da enxada ou da rabiça do arado, que primeiro fizeram correr, sobre a sua pele infantil, o acre suor com que háde comer o pão. Assim, não admira que seja através das velhas cidades, que se não despiram ainda da pele dos tempos «coloniais», que podemos 
surpreender, no Brasil, as marcas mais persistentes da sua formação portuguesa.

Sem outra pretensão que não fosse a de aproximar coisas distantes, com o fim de as colocar à luz de melhor entendimento, de estabelecer, através de similitudes evidentes, tipos de cidades e parentescos de ambientes urbanos, seria possível trazer, à interpretação da paisagem humana do Brasil, um exemplo do ponto de vista comparativo, brilhantemente ilustrado na Sociologia e na Etnologia, mas só rara e fugazmente ensaiado no domínio dos estudos geográficos ${ }^{2}$.

${ }^{2}$ Para um ensaio deste género, que desejava fazer e de que outros trabalhos me forçaram a abrir mão, se deixam estas páginas liminares, escritas depois da minha primeira viagem ao Brasil em 1952 [1966]. 